\title{
Legislative advances in
}

\section{financial stability in the US - the Wall Street Reform and}

\section{Consumer Protection Act 2010}

\author{
by Priya Nandita Pooran
}

$\mathrm{O}$ n July 15, 2010, the US Senate passed legislation aimed at promoting financial stability. Among the aims of the Wall Street Reform and Consumer Protection Act 2010 (HR4173 - "Wall Street Reform 2010"), which was signed into law on July 21, is the promotion of financial stability by enhanced accountability and transparency in the financial system, to end bailouts, and consumer protection from abusive financial services practices. In addition, the Wall Street Reform 2010 will seek to (a) increase the scope of the Federal Reserve; (b) address the key issue of effective insolvency arrangements in the context of "large, interconnected financial institutions; (c) improve regulation of over-the-counter derivatives and hedge funds; (d) seek to improve regulation of bank and savings association holding companies and depository institutions; (e) create an Office of National Insurance; and (f) provide increased shareholder rights for executive compensation and corporate governance.

This legislation remains one of the most significant enactments in financial systems and regulation to date. Not only does this mark an important national legislative and regulatory advance, it further provides instructive insights into international approaches and advances inter alia in the areas of financial stability, insurance regulation and systemic risk management and related institutional and regulatory capacity in these areas.

The most potentially significant institutional changes of Wall Street Reform 2010 include the introduction of a Financial Stability Oversight Council (FSOC) in Title 1, an Office of National Insurance within the Treasury (Title V) and a Bureau of Consumer Financial Protection to be located within the Federal Reserve (Title X).

It is evident from the recent financial crisis that the need to achieve better understanding, oversight and assessment of systemic risk in the financial system - not fragmented on a sectoral or industry level - is an important area of regulatory reform needed to enhance the resilience of the financial system and protect against financial crises of similar origins as the recent crisis. The proposed US framework, in particular the introduction of the FSOC to address comprehensively risk in the financial system, recognises and highlights the importance and key role of systemic risk in the new regulatory approach - in policymaking, regulatory frameworks and institutional design. It also raises parallels with the approaches of other countries in addressing this key regulatory challenge.

This article seeks to address recent legislative and regulatory changes in the US in the area of systemic risk management and to assess the impact of the changes on financial market supervision. It also addresses changes to the regulation of insurance markets, the enhancements to systemic risk monitoring and the effectiveness of the proposed consumer protection bureau.

\section{SYSTEMIC RISK}

The term "systemic risk" has during the recent crisis been widely used as a popular term in the regulatory reform debate. Despite the concept of systemic risk being broadly acknowledged as a key area for policy reform, there is a need to clearly define its meaning to avoid ambiguity over the concept and to fully understand its role and relevance in contributing to the crisis and in the reforms. Systemic risk is inextricably intertwined with the concept of contagion in the financial markets and could be described as the domino effect that single event failures or weaknesses in the financial sector could have on the broader system, or alternatively the translation of weaknesses in one sector on different sectors or institutions - and beyond the potential impact (of such events and weaknesses) on the broad financial sector and on the national and global economy.

Traditionally, systemic risk has been most closely identified with regulation of the banking system. This has however been changed by a number of factors including 
the evolution of the financial markets, the globalisation of finance and the shared commercial context in which financial institutions operate and for which financial instruments can be now employed. Consequently, risks formerly associated with and assumed as being contained within a distinct area of the financial system may now arise from different financial institutions and sources, and systemic risk has broader significance throughout the financial sector. It therefore needs to be addressed in the context of the banking, insurance and securities industries while maintaining a focus on consumer protection objectives.

As finance has outpaced regulation in its evolution and development, instruments such as guarantees, credit default swaps and reinsurance products may in international financial transactions be employed by financial institutions to perform commercial functions in the transactional market. Given this parallel, when similar products are subjected to distinct regulatory treatment and supervisory oversight, weaknesses on a system wide level could be more difficult or take longer to perceive from a regulatory perspective and result in delayed corrective policy actions. Thus, systemic risk needs to be considered and understood in its commercial context and with related financial sector and economic implications.

\section{OVERSIGHT OF SYSTEMIC RISK UNDER THE NEW LAW}

The US framework makes several far-reaching changes to the current regulatory approach, institutional design, allocation of responsibility and decision-making in supervisory and policy terms. One of the fundamental changes of the new legislation is the introduction of the Financial Stability Oversight Council, the role of which is broadly comparable to the European Systemic Risk Council (ESRC) to be introduced in the European Union.

The FSOC shall consist of both voting members and non-voting members. It shall comprise the Secretary of the Treasury as chairperson, the Chairman of the Board of Governors of the Federal Reserve System, the Comptroller of the Currency, the Director of the Bureau of Consumer Financial Protection (to be formed under the new law), the Chairman of the Securities and Exchange Commission, the Chairperson of the Federal Deposit Insurance Corporation, the Chairperson of the Commodity Futures Trading Commission, the Director of the Federal Housing Finance Agency and an independent member with insurance expertise. The legislation also provides for the Director of the Office of Financial Research, (to also be introduced under Wall Street Reform) to serve in an advisory capacity as a non-voting member.

The purposes of the Financial Stability Oversight Council are three-fold (s 112): financial distress or failure of large, interconnected bank holding companies or nonbank financial companies";

2. the promotion of market discipline by eliminating expectations on the part of shareholders, creditors and counterparties of such companies" that, in the event of a failure, the Government will shield them; and;

3. to respond to emerging threats to the stability of the United States financial markets.

The proposal not only represents a major institutional change in the US financial and regulatory structure but further brings to the fore new regulatory and policy considerations in addition to those it seeks to resolve. One such example arises from the representation for the insurance sector at the FSOC by [the designation of] an "independent member." This highlights the state-by-state system of regulation for the insurance industry and the need to address the fragmented supervisory structure at present employed for oversight of the insurance sector (It is noteworthy that the "state insurance authority in which an insurance company is domiciled" is designated under the Wall Street Reform 2010 as the "primary financial regulatory authority" - s 2(11)(D)). With the persistence of a state-by-state system of supervision, not only is there no national body with over-arching broad national oversight of risks, trends and vulnerabilities in the insurance market to convene with other national sector representatives, but this also poses a potential obstacle for future international coordination for the insurance industry in the United States.

Second, the FSOC's ambit as the identification of risks to financial stability that could potentially arise from "the material financial distress or failure of large, interconnected bank holding companies or non-bank financial companies" (s 112(a)(1)(A)) is arguably more restrictive in terms of scope than it could be. In particular, the provision of the FSOC with broader, far-reaching and general systemic risk management powers could provide this body with wider powers to assess threats to financial stability whether or not arising from large banking and non-banking financial institutions. It is arguable that in the current state of global finance, all institutions are to some degree inter-connected - hence the importance of assessing translation and sharing of risks within the system. In particular, potentially disruptive risks may emerge from smaller institutions. It is important to avoid the assumption that institutional size may bear a direct correlation to the probability and scope of threats of financial stability. While it is safe to assume that larger institutions may exert a more significant market influence, this is not always the case and account must be taken of the potential for smaller institutions and a variety of other factors to also be the source of risks to financial stability. Therefore, the question arises as to whether the FSOC is intended to identify only major institutional failures - and the possible impact on the system from this, or broader risks to the financial 
system whether or not arising from this particular sort of failure.

Third, it is unclear how the proposals eliminate the expectations on the part of shareholders and creditors that the government shall shield them in the event of failures. While increased financial stability would evidently be intended to reduce the occurrence of failure events, this issue could be treated separately from that of the government's response and level of support in the wake of such events. Failure events, while undesirable in financial stability terms, cannot be entirely eliminated. Such an expectation would be unrealistic, and, more importantly, an inappropriate measure of the success of the FSOC. The promotion of financial stability is an important objective in its own right which hopefully will reduce the likelihood of financial institution failures. However, the burden of providing support in the event of such failures is a matter that may best be treated separately, whether as an issue of industry-funded support mechanisms or other policy responses.

Fourth, the FSOC has the ability under the legislation to require both US and foreign non-bank financial institutions to be supervised by the Federal Reserve. In the former case, this may occur in the event of "material financial distress" that could pose a threat to national financial stability, and in the case of foreign non-bank financial institutions where such entities have "substantial US assets or operations" and their financial distress may also pose a threat to US financial stability. The scope of the Council's power in these circumstances represents the significantly heightened powers granted to the Federal Reserve under the law, as well as raising the extraterritorial implications of enabling the Council to require foreign non-bank institutions to be subject to prudent standards and supervision by the Federal Reserve.

Fifth, it is clear that the FSOC shall be engaged in identifying potentially disruptive areas of risk but that its role shall have a broader policy function including respondingto such threats by making policy recommendations to primary financial regulators (s $112(\mathrm{a})(1)(\mathrm{C}))$. The latter carries with it a range of further implications. The legislation is both comprehensive and forward-looking in that it maintains the primary jurisdiction of existing regulators and thereby reinforces the delicate balance of micro-prudential supervision to be conducted by primary financial regulators, and macroprudential oversight to be exercised by the Council.

\section{OTHER CHANGES INTRODUCED BY THE NEW FRAMEWORK}

The reforms seek to comprehensively reflect the concern in modern-day finance over systemic risk arising from disparate and non-traditional areas of the financial system. One important way in which it seeks to provide a system-wide approach to risk is by the requirement for centralised clearing of standardised derivative contracts. This recognises the commercial and regulatory possibility for systemic risk to arise in complex derivative markets and in the broader wholesale capital markets. Further, the Volcker Rule prohibits banks from investing more than 6 per cent of their capital in proprietary trading and from using deposit money to be invested in hedge funds or private equity.

The establishment of the Office of National Insurance ("ONI") is another significant institutional change introduced by the new legislation. Its responsibilities shall include:

- monitoring all aspects of the insurance industry (including identifying issues or gaps in the regulation of insurers that could contribute to a systemic crisis in the insurance industry or the financial system);

- provision of recommendations to the FSOC on the designation of an insurer, as an entity subject to regulation as a nonbank financial company supervised by the Board of Governors;

- provision of assistance in administration of the Terrorism Insurance Programme;

- coordination of federal efforts and development of federal policy on prudential aspects of international insurance matters;

- conduct of consultation with the states (including state insurance regulators) regarding insurance matters of national importance and prudential insurance matters of international importance;

- performance of such other related duties and authorities as may be assigned to the Office by the Secretary.

The ONI shall advise the Secretary on major domestic and prudential international insurance policy issues and the legislation provides for the conduct of a study to be submitted to Congress on modernisation of US insurance regulation. This shall include consideration of systemic risk regulation in insurance, consumer protection for insurance products and practices (including gaps in state regulation), the degree of national uniformity of state insurance regulation, consolidated regulation of insurance companies and affiliates, and international coordination of insurance regulation.

While the ONI does not at present have a role on the FSOC, its introduction recognises the importance of greater harmonisation, co-ordination and consistency at the national level of legislation, regulatory policy and supervision of insurance entities. The proposed study envisaged by the legislation may be viewed as a precursor to greater federal supervision in this sector and harmonisation of insurance regulatory frameworks, thereby enhancing risk management and eliminating inconsistencies which do not serve well for the assessment of national systemic risk and could be exacerbated by the 
current system of state authorities and divergent frameworks.

\section{CONCLUSION}

In conclusion, it appears that the treatment of systemic risk in the financial system will be significantly enhanced by the enactments of the Wall Street Reform and Consumer Protection Act of 2010. The effectiveness of the Act in increasing surveillance of system-wide risk and providing more centralised oversight will facilitate timely, targeted policy responses, and this is indicated by the degree of integration and reflection of systemic risk management throughout the proposals and regulatory institutions. The Act will have an effect beyond providing a greater degree of regulatory information as to such risk in a way that will provide useful monitoring of weaknesses in the financial system and the possibility of averting future crises; the impact of Wall Street Reform 2010 on the current structure for financial institution governance in the US is likely to result in a less fragmented regulatory design, and greater concentration of supervisory control in the Federal Reserve.
The passing of Wall Street Reform 2010 is a clear recognition of the need to address in regulatory terms the cross-border nature of finance, risk and international financial transactions, to afford due consideration for issues of systemic risk throughout the financial system, and address stability, risk and contagion on national and regional levels. While the measures will provide enhanced surveillance and stability for financial markets, the true effectiveness of Wall Street Reform lies in the faithfulness of its implementation by national regulatory agencies in the US. Ultimately, an international co-ordinating mechanism in this area of financial stability would provide a greater measure of global oversight and offer the possibility of averting significant future global financial crises in circumstances where the appropriate exchange of information and risk analysis could allow for timely policy actions, appropriate interventions and global policy coordination.

Priya Nandita Pooran

LLM, Attorney-at-law 